\title{
TITLE
}

\section{Attitudes to a Male Contraceptive Pill in a group of Contraceptive users in the UK}

\author{
Author \\ Dr Susan Walker MB BCH PhD (Corresponding Author) \\ Present Address (Corresponding Address) \\ Anglia Ruskin University \\ William Harvey Building \\ Rivermead Campus \\ CHELMSFORD \\ CM1 1SQ \\ United Kingdom \\ Tel: +44 $1245493131 \times 4663$ \\ Email: susanwalker@anglia.ac.uk \\ Affiliation Address \\ Department of Social and Political Science \\ University of Cambridge \\ Free School Lane \\ CAMBRIDGE \\ CB2 3RQ \\ United Kingdom
}




\section{ABSTRACT}

BACKGROUND. Small scale trials of male hormonal contraception have produced encouraging results. Attitudes to and beliefs about a proposed male pill may affect uptake. METHODS This paper examines attitudes towards a proposed 'male contraceptive pill' among a self selected sample of 54 men and 134 women, living in a non-metropolitan centre in the East of England, United Kingdom who were already users of contraception. Thirty four respondents were also interviewed and their views on the male pill were qualitatively analysed.

RESULTS. The acceptability of a male pill was high with just under half (49.5\%) of respondents indicating that they woud use it. Gender, length of relationship, age and educational achievement did not affect the reported acceptability. $42 \%$ of respondents expressed concerns that men would forget to take a male pill. Women were significantly more likely to express this concern than men. $26 \%$ of respondents expressed health concerns. Willingness to take a male pill was associated with expressing the view that increased protection against pregnancy would be an advantage of such a method. Those unwilling or undecided were more likely to express concerns about the effect of a pill on future fertility.

CONCLUSIONS. A male pill was accepted as a potential aid to increased fertility control by a large proportion of convenience sample of contraceptive users in the East of England. If a male pill were to be marketed in the UK this study suggests that concerns about effects on future fertility and health risks may need to be addressed.

\section{KEYWORDS.}

Male contraception; Fertility control; Knowledge, attitudes, practice; England 


\section{INTRODUCTION}

Successful trials of male hormonal contraception have been carried out in small numbers of human volunteers (1-5). The World health Organisation has stated its backing for the urgent development of male factor contraceptive methods to supplement vasectomy and condom use (6).

A recent review of the acceptability of male hormonal contraception indicated that there was a general willingness to consider the method but that attitudes and acceptability varied by country (7). Heinemann et al.(2004) conducted a large multinational study of 9000 men from nine countries on four continents, in which men responded to questions regarding their personal experience of contraception, and whether they would be willing to use a new method of male fertility control (MFC) "capable of preventing sperm production and thus pregnancy" (8). They found that overall more than $55 \%$ of men expressed willingness to use such a method, with a range between countries of 28.5-71.4\%. Martin et al. (2000) carried out an international survey involving 1829 men in Edinburgh, Hong Kong, Shanghai and Cape Town to access male attitudes to proposed new hormonal methods of male contraception (9). Martin et al. found that willingness to use MHC varied between 44\%-83\% depending on the country surveyed. They found that men were concerned about the efficacy of such a preparation, about the convenience of its use, and about a MHC causing a reduction in sexual satisfaction and masculinity, but these concerns varied in frequency between the countries surveyed. Glasier et al. (2000) conducted a survey in identical centres of population looking at the attitudes of women to a MHC (10). A total of 1894 women were recruited from family planning clinics. There was considerable inter-country variation in acceptability. Only $2 \%$ of all women surveyed 
would not trust their partner to use such a method. More recently Eberhardt, van Wersch \& Meikle (2009) reported the results of a survey of an opportunistic sample of 220 men and women (110 matched pairs) in the UK from in which attitudes to a male contraceptive pill were investigated using a novel scale (11). They found that women expressed more favourable attitudes towards a male pill, but that men were more likely to indicate that they could be trusted to use such a pill effectively. Men in stable sexual relationships expressed a more favourable attitude to a male pill than men in casual or no relationships.

Brooks (1998), who examined the views of heterosexual males in the UK, suggested that the male pill would prove most popular among professionals, aged 36-45 years who were in a relationship where contraceptive responsibility is shared and sexually transmitted infections (STIs) were not a concern (12).

To date there has been surprisingly little detailed exploration of attitudes to the male pill in the United Kingdom (UK). The UK has high rates of abortion and teenage pregnancy compared to its European neighbours. The attitudes, concerns and expectations surrounding the prospect of a male contraceptive pill are likely to influence its uptake. Exploring the associations between acceptability, attitudes and certain demographic characteristics may help to guide clinicians, pharmaceutical companies, educators and policy makers in the event of a male hormonal contraceptive method becoming licensed and available for use.

This research project sought to explore the views of contraceptive users in a region of England regarding a male pill. It investigated not only the extent of willingness to use a male contraceptive pill but also the attitudes, hopes and concerns which lay behind this stated willingness. 


\section{SUBJECTS, MATERIALS and METHODS}

134 women and 54 men in the UK were asked to indicate whether or not they would use a male pill as a form of contraception.

Questionnaires were completed anonymously and in private and were returned to the researcher by via a pre-paid envelope. A sub-sample of respondents was interviewed.

\section{Ethical Approval}

Ethical permission was obtained from Cambridgeshire 3 NHS Research Ethics Committee (06/Q0106/78). Fully informed written consent was obtained from all participants.

\section{Sample}

The research was carried out in a relatively prosperous, non-metropolitan area of the east of England. The sample was self selected initially from clients attending an NHS Family Planning Clinic (FPC) and choosing to answer an anonymous self administered questionnaire. Men and older respondents were not well represented in the respondents derived from the FPC. As a response to this, social and occupational groups were targeted and invited to take part in the survey. Thus the sample is a convenience sample in which efforts were made to extend the age and gender diversity. After 12 months of sampling 412 questionnaires had been distributed and 188 respondents had returned completed questionnaires and were included in the analysis. This represents a response rate of $46 \%$.

In Table 1 percentages exclude missing responses.

(Table I).

Respondents were asked to indicate on the questionnaire if they would be willing to take part in an interview. A convenience sample of sixteen women and eighteen men were interviewed on a range of issues concerning contraception. 


\section{Questionnaire Construction}

A questionnaire was constructed which asked about demographic characteristics, experience of and beliefs about contraception, attitudes towards the male pill and previous experience of unexpected pregnancy. The face validity was improved using 3 focus groups, chosen to reflect the age and gender diversity of the expected respondents. (A copy of the questionnaire is available to reader on request).

\section{Outcome variables and analysis}

Respondents were asked to indicate whether or not they would be prepared to use (male) or allow their sexual partners to use (female) a 'male pill' as their form of contraception. The question did not clarify the method of action of a putative male pill so the responses refer to the respondent's subjective perception of what a male pill would entail.

Their responses were indicated along a ranking of 'Yes', 'Not sure' and 'No'. They were then prompted to enter free text replies under the headings;

"What would be the advantages of this method?"

"What concerns would you have about a 'male pill'?"

"What kind of information would you need before deciding to use it?"

Not all respondents answered the question and of these not all chose to enter free text replies.

Associations between 'willingness' and other variables were analysed using the $\chi^{2}$ test or Fisher's exact test. Where rankings could be considered ordinal a Mann-Whitney test was used. 
The free text remarks made by respondents were analysed by theme. There were 41 differing themes or categories noted and the incidence of occurrence of each category was recorded. Most respondents were concerned with more than one theme. The ensuing figures refer to the percentage of overall respondents who mentioned each particular theme in the course of their remarks. Since remarks were made in free text and at the discretion of the respondents, where a figure is given for agreement with a view or concern it should not be assumed that the remainder of respondents were in disagreement.

Concerns and remarks were grouped according to whether or not a concern/remark was expressed (Expressed/Not expressed) and the resulting percentage of respondents was analysed using cross tabulation and tests of association as above.

\section{Qualitative interviews}

The interviews were semi-structured and the question regarding views on a potential male pill was one of a number of topics explored. Attention was drawn to the topic of the male pill in the questionnaire and respondents were invited to give their views upon the proposed method. Interviews were transcribed and analysed thematically using NVivo software. All names are pseudonyms.

\section{RESULTS}

Overall $49.5 \%$ of respondents who replied indicated that they would be prepared to use a male pill, $19.2 \%$ declined to use one, and $31.3 \%$ were unsure. 6 respondents did not answer $(\mathrm{N}=188)$. Responses of men and women were very similar.

Gender, length of relationship, age and educational achievement did not affect the reported acceptability. 


\section{Remarks and Concerns}

\section{Health Based Concerns}

\section{Quantitative findings}

The largest category of remarks referred to concerns about possible side effects of a male pill. Overall 53\% of respondents mentioned this.

$26 \%$ mentioned concerns specifically about adverse health effects, risks or safety. Men in a long-term relationship were significantly less likely to express concerns over health effects compared to men not in a long term relationship (30.8\% v. $70.0 \%)$ $(\mathrm{p}=0.023)$

\section{Qualitative Findings}

The theme of possible side effects of the male pill also emerged strongly from the interview data. Experience of and knowledge about the effects of the female contraceptive pill informed views about a male pill. Respondents were concerned with long-term, potentially serious health risks and short term effects on emotions and behaviour.

'I think, I don't think it would be very popular. I think a lot of people would feel very similar to what I do which is that when the pill, when the female pill was new, there were lots of horror stories around, and even now, cause the female pill is still fairly new isn't it. There's safer alternatives and certain ones were linked to different types of cancer. And you just wouldn't know and nobody can know until fifty years down the line." (Ezra) 
"So I was thinking yea, I think that's something I'd certainly want to know if it was going to affect my outlook, my desire or performance or things like that. " (Norman)

There were some concerns expressed about whether a male contraceptive pill would be truly reversible or whether it would have longstanding detrimental effects on male fertility.

"I mean it would just be comforting because it would be a guarding against pregnancy so that would be good. But I guess that would be...I'd want to know it wasn't going to have any long term effects on my fertility cos I'd probably like to have kids at some point." (Jacob)",

\section{Relationship Based Remarks}

Quantitative findings

Significantly more women $(\mathrm{N}=70)$ than men $(\mathrm{N}=9)$ expressed the concern that men would forget to take a pill regularly $(52 \%$ v. $17 \%)(\mathrm{p}<0.001)$. Overall $42 \%$ of respondents expressed this concern.

Significantly more men $(\mathrm{N}=13)$ than women $(\mathrm{N}=2)$ expressed the view that increased male control over paternity would be an effect of using a male pill (24\% v.1.5\%) (Fisher's Exact test $<0.001$ ).

Qualitative Findings

Three of the eighteen men interviewed were concerned that they would forget to take a daily pill. For this reason two of the three favoured a monthly injection to overcome this problem. 
"You know, you forget or you get busy and it just slips your mind so I think it's a good idea. I think probably it's a step in the right direction but I think probably it should be, you know, injections which last longer as opposed to this daily routine that you have to adhere to." (Liam)

Increased control over paternity was seen as an advantage of a male pill by some of the interviewees, both male and female. There was recognition that male condoms had limitations, and that men often had to rely on their female partners to prevent an unwanted pregnancy.

"On the other hand I mean the condom is not particularly reliable as a contraceptive so it would give me more control in that I could choose that I was... I mean you do hear stories about women deciding they're going to get pregnant without letting their men know [...] it would be nice to be in control in that respect." (Ross)

"I think the male pill is an effective form of contraception for the men that are worried about being trapped. About having one night stands and a condom breaking." Gloria)

In contrast to somewhat negative concerns about trust and control, a more positive aspect of a proposed male pill, expressed by interviewees, was the chance for shared responsibility within a relationship. The idea of a 'better man' who took responsibility for protecting both partners from unwanted pregnancy was constructed by two of the female interviewees. 
"I think it would show that he was responsible. I wouldn't see him as any less of a man. If anything I'd see him as a better man because he's responsible enough to know and to protect both of us really." (Gloria)

'I'd think he was more responsible, more mature than most guys (if he was taking a male pill)[...] I'd think better of him probably." (Laura)

"I think it could be a good thing. And I think that men should bear the responsibility of this as much as women. Cos I know some women will be on the pill and it will cause them quite a lot of problems both physically and mentally. So I think men should share in that. Would I take it? If I was in a long-term relationship with someone and I felt that his something that was going to make our lives better, yes, I would." (David)

\section{Remarks regarding Presently Available Contraceptive Methods}

Quantitative findings

$37 \%$ of male respondents expressed a view that a male pill would be preferable to using either condoms or withdrawal.

Qualitative Findings

Three of the eighteen male interviewees explicitly reported a dislike of condoms and favoured a potential male pill for that reason.

Conversely three men thought that they would still prefer to use condoms even if a male pill was available. The reasons for this varied and the ease of use, visibility and inherently low health risks of condoms were cited. 
"I think a lot of people would have issue with taking something daily or weekly or monthly. I think the thing with condoms is that it's relatively easy to do. You know that it offers a good level of protection and that it's sort of safe fundamentally so... personally I would probably lean towards something that was used as and when as opposed to having it in your system the whole time." (Kelvin)

"The pill has never even crossed my mind before. It makes me feel a little bit...I'd want to know it definitely works because with the condom you can stop anything coming out. You know it's there, you know. It's not going anywhere. If it breaks you know it's broken but if there's a pill and you have to trust science." (Harold)

An additional reason for preferring condoms was the dual effect of preventing pregnancy and preventing sexually transmitted infections (STIs). The underlying concern was that male pill use may have the effect of increasing rates of sexually transmitted infections.

"Certainly with the added advantage of the condom protecting from sexually transmitted diseases far better. Well, the male pill wouldn't offer any protection so I can see there being issues in that respect cos people move from 'if I'm taking the pill then I don't worry about pregnancy' and may stop then using condoms as I certainly know from a personal point of view. That contraception is thought of as a way of stopping pregnancy rather than stopping sexually transmitted disease. So yea, in that respect I think it could be dangerous." (Obadiah) 
"I mean I think for me it's quite simple. I mean one of the reasons I'm using it is to prevent any infection so that means it's the condom does that." (Ross)

\section{Remarks on Male pill according to willingness to use method}

\section{Quantitative Findings}

In order to explore how attitudes and concerns were associated with willingness to use a male pill, respondents were divided into those who were willing to use a male pill ('Yes') (N=83), and those whose response was negative or undecided ('No'/'Maybe') $(\mathrm{N}=88)$, and the percentage frequency of remarks or concerns about a male pill for each group was calculated.

Those willing to take or use a male pill ('Yes') were more likely than the undecided or unwilling group to cite 'Increased protection against pregnancy' as an advantage of a male pill $(14.4 \%$ v. $4 \%)(p=0.02)$

Those unwilling or undecided about using a male pill ('No/Maybe') were significantly more likely to express concerns about effects on future fertility than those willing ('Yes') to use the method $(20.9 \% \mathrm{v} .10 .0 \%)(\mathrm{p}=0.043)$

\section{Qualitative Findings}

A minority finding emerging from the qualitative interviews which may affect the acceptability of the male pill was an association between pill-taking and femininity. This was usually elicited following a question regarding whether a male pill would affect the perceived or self-perceived masculinity of a man.

“Em, it's a strange idea. But I think only strange because I'm so used to women taking the pill and it's something you associated with women the word 'the pill' you just immediately think of a woman." (Ian) 
“But I think just because you've got such strong associations between pills and women. It just seems a bit odd." (Paul)

"I mean the image of, the manly image whether it be the sportsman or whatever you might see on the billboards, probably does lend itself to a reluctance to take something like a male oral contraceptive pill and so the use of a condoms which doesn't diminish you in any way but just merely stops the outcome, probably lends itself to that image. "(Obadiah)

\section{DISCUSSION}

The high rate of acceptability of a male pill within this sample is comparable with findings from other surveys $(8-10,13)$. This research suggests that this acceptability may be due to men welcoming the increased control over unplanned paternity, and the removal of the need to rely on a partner for effective contraception.

However concerns about health risks and reversibility may need to be specifically addressed by those promoting male hormonal contraception. Experience of the female contraceptive pill appears to have made potential users of contraception very aware of the potential for long term side effects. What long term effects will become apparent in post marketing surveillance, and whether men will be prepared to accept these, will play a role in the commercial and clinical viability of male hormonal methods. The acceptability of a potential male hormonal pill may also have been due to dissatisfaction with condoms. However within the qualitative data the findings are more nuanced with some men expressing a dislike of condoms, but others expressing a preference for their visibility and simplicity. 
That just over half (52\%) of women were concerned that a male partner would forget to take the pill is in contrast to the findings of Glasier et al. (2000) who found that only $2 \%$ of their female respondents would not trust a partner to use a male pill (10). Issues of trust were expressed in the qualitative data and there was a tension between acknowledgement of the opportunity to share responsibility, and concerns, from female interviewees, about whether men would prioritise the need to avoid pregnancy. It remains to be seen whether the attitudes expressed regarding a male contraceptive 'pill' will extend to contraceptive implants or injections. The doubts expressed by male interviewees about their own ability to remember to take a daily pill and the expressed preference, by a few, for an injectable or long acting male method may indicate that injectable hormonal methods may be acceptable because of their convenience.

Concerns about pills being associated with femininity may also favour an injectable method. These preferences and concerns are of interest because the most successful male hormonal methods, trialled to date, have used injectable hormones as opposed to an oral 'pill'.

\section{Strengths and Limitations of Study}

Participants in this survey were not randomly sampled, nor were they matched, so comparisons between male and female responses, and significant associations reported between demographic characteristics and responses must be treated with some caution. 


\section{References}

(1) Amory JK. Progress and prospects in male hormonal contraception. Curr Opin Endocrinol Diabetes Obes 2008;15(3):255-60.

(2) Brady BM, Amory JK, Perheentupa A, Zitzmann M, Hay CJ, Apter D, et al. A multicentre study investigating subcutaneous etonogestrel implants with injectable testosterone decanoate as a potential long-acting male contraceptive. Human Reproduction 2006;21(1):285-294.

(3) Grimes DA, Lopez LM, Gallo MF, Halpern V, Nanda K, Schulz KF. Steroid hormones for contraception in men. Cochrane Database of Systematic Reviews 2007(2)

(4) Liu PY, Swerdloff RS, Anawalt BD, Anderson RA, Bremner WJ, Elliesen J, et al. Determinants of the rate and extent of spermatogenic suppression during hormonal male contraception: An integrated analysis. Journal of Clinical Endocrinology \& Metabolism 2008;93(5):1774-1783.

(5) Mommers E, Kersemaekers WM, Elliesen J, Meuleman EJH, Kepers M, Apter D, et al. Efficacy and safety of etonogestrel and testosterone undecanciate for male hormonal contraception. European Urology Supplements 2008;7(3):217.

(6) WHO. Promoting Family Planning - Contraceptive technology - Broadening the range of products. 2010; Available at:

http://www.who.int/reproductivehealth/topics/family_planning/broadening/en/index.h

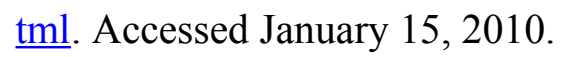


(7) Glasier AF. Acceptability of contraception for men: a review. Contraception 2010;82:453-456.

(8) Heinemann K, Saad F, Wiesemes M, White S, Heinemann L. Attitudes toward male fertility control: results of a multinational survey on four continents. Human Reproduction 2005;20(2):549-556.

(9) Martin CW, Anderson RA, Cheng L, Ho PC, van dS, Smith KB, et al. Potential impact of hormonal male contraception: cross-cultural implications for development of novel preparations. Hum.Reprod. 2000;15:637-645.

(10) Glasier AF, Anakwe R, Everington D, Martin CW, Spuy Zvd, Cheng L, et al. Would women trust their partners to use a male pill? Hum.Reprod. 2000 March 1;15(3):646-649.

(11) Eberhardt J, van Wersch A, Meikle N. Attitudes towards the male contraceptive pill in men and women in casual and stable sexual relationships. Journal of Family Planning and Reproductive Health Care 2009;35(3):161-165.

(12) Brooks M. Men's views on male hormone contraception -- a survey of the views of attenders at a fitness centre in Bristol, UK. Br.J.Fam.Plann. 1998 Apr, 24 (1);24(1):7.

(13) Marcell AV, Plowden K, Bowman SM. Exploring older adolescents' and young adults' attitudes regarding male hormonal contraception: applications for clinical practice. Hum.Reprod. 2005 November 1;20(11):3078-3084. 